\title{
Technology-Supported Self-Guided Nutrition and Physical Activity Interventions for Adults With Cancer: Systematic Review
}

Nicole Kiss ${ }^{1,2}$, BSc, MNutDiet, PhD; Brenton James Baguley ${ }^{3,4}$, BHSc, MNutrDiet; Kylie Ball ${ }^{1}$, BA, PhD; Robin M Daly $^{1}, \mathrm{PhD}$; Steve F Fraser ${ }^{1}, \mathrm{PhD}$; Catherine L Granger ${ }^{5,6}, \mathrm{PhD}$; Anna Ugalde ${ }^{7}, \mathrm{PhD}$

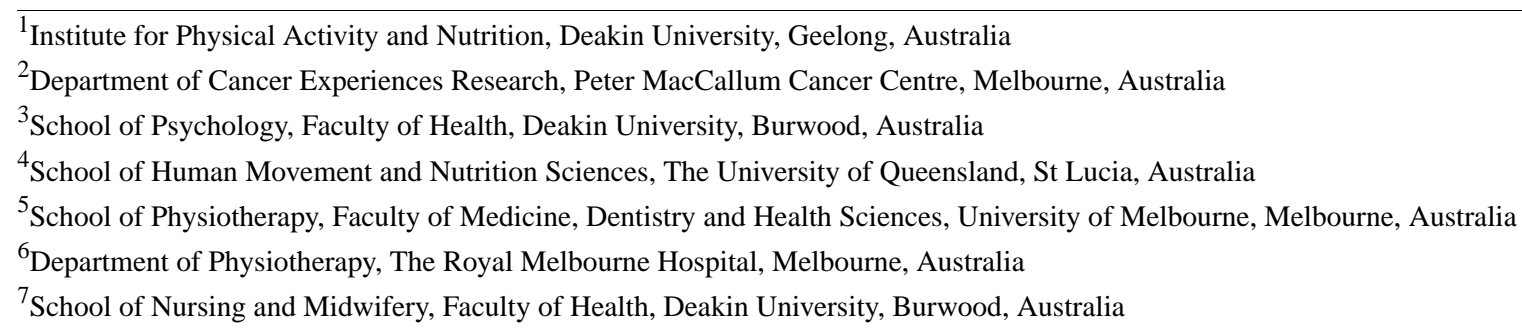

Corresponding Author:

Nicole Kiss, BSc, MNutDiet, PhD

Institute for Physical Activity and Nutrition

Deakin University

Geelong,

Australia

Phone: 61392468858

Email: nicole.kiss@deakin.edu.au

\section{Abstract}

Background: Nutrition and physical activity interventions are important components of cancer care. With an increasing demand for services, there is a need to consider flexible, easily accessible, and tailored models of care while maintaining optimal outcomes.

Objective: This systematic review describes and appraises the efficacy of technology-supported self-guided nutrition and physical activity interventions for people with cancer.

Methods: A systematic search of multiple databases from 1973 to July 2018 was conducted for randomized and nonrandomized trials investigating technology-supported self-guided nutrition and physical activity interventions. Risk of bias was assessed using the Cochrane Risk of Bias tool. Outcomes included behavioural, health-related, clinical, health service, or financial measures.

Results: Sixteen randomized controlled trials representing 2684 participants were included. Most studies were web-based interventions $(n=9)$ and had a 12-week follow-up duration $(n=8)$. Seven studies assessed dietary behaviour, of which two reported a significant benefit on diet quality or fruit and vegetable intake. Fifteen studies measured physical activity behaviour, of which eight studies reported a significant improvement in muscle strength and moderate-to-vigorous physical activity. Four of the nine studies assessing the health-related quality of life (HRQoL) reported a significant improvement in global HRQoL or a domain subscale. A significant improvement in fatigue was found in four of six studies. Interpretation of findings was influenced by inadequate reporting of intervention description and compliance.

Conclusions: This review identified short-term benefits of technology-supported self-guided interventions on the physical activity level and fatigue and some benefit on dietary behaviour and HRQoL in people with cancer. However, current literature demonstrates a lack of evidence for long-term benefit.

Trial Registration: PROSPERO CRD42017080346; https://www.crd.york.ac.uk/prospero/display_record.php?RecordID=80346

(JMIR Mhealth Uhealth 2019;7(2):e12281) doi: $\underline{10.2196 / 12281}$

\section{KEYWORDS}

cancer; diet; exercise; nutrition; physical activity; self-guided interventions; technology 


\section{Introduction}

It is estimated that over 32 million people are living with cancer worldwide [1], and the predicted global incidence of cancer is estimated to increase from 14 million new cases in 2012 to more than 17 million in 2020 [1]. Cancer is now considered a chronic disease, and the number of cancer survivors in the United States is estimated to exceed 20 million by 2026 [2]. This rapid increase is adding pressure on health care systems to cope with the growing number of people requiring treatment while maintaining high-quality health care. As a result, there is a need to consider alternative, easily accessible, and flexible models of delivering care, in particular, supportive care interventions, to people with cancer in order to reduce the demand for clinical resources while maintaining optimal clinical and health outcomes.

Nutrition and physical activity interventions are vital components of cancer care [3]. Prevalence studies demonstrate that as many as $40 \%$ of cancer patients are affected by malnutrition, which is associated with increased mortality and health care costs and poor health-related quality of life (HRQoL) [4-6]. Sarcopenia, the loss of skeletal muscle mass, strength, or function, is present in $25 \%-57 \%$ of cancer patients and is an independent predictor of survival [7-9]. Nutrition and exercise interventions can improve muscle mass, muscle strength, physical function, nutritional status, fatigue, and HRQoL for people undergoing cancer treatment $[4,5,10,11]$. Preliminary evidence also shows potential for improved survival from nutrition interventions delivered throughout treatment $[12,13]$. Conversely, obesity after treatment completion is associated with reduced cancer survival; nonetheless, less than $20 \%$ of cancer survivors meet the dietary recommendations and less than $50 \%$ meet the physical activity recommendations, demonstrating a clear role for interventions to support healthy eating behaviors and increased physical activity [14-19]. Nutrition and physical activity interventions, particularly in survivors of breast cancer and men with prostate cancer treated with androgen-deprivation therapy, have been shown to produce clinically meaningful, beneficial weight loss or improvements in muscle mass and cardiometabolic health outcomes (eg, reduced insulin resistance and low-density lipoprotein cholesterol levels) [20,21]. Further, exercise training following a cancer diagnosis has a protective effect on cancer-specific mortality, cancer recurrence, and all-cause mortality [10].

Technology-based platforms such as the internet, mobile phone or tablet apps, and telehealth and wearable devices provide a unique opportunity to deliver broad-reaching interventions and health care to people with cancer. In the general population, technology-supported nutrition and physical activity interventions have demonstrated positive, albeit modest, benefits of increasing physical activity levels, reducing dietary fat intake, and increasing fruit and vegetable consumption [22-24]. In cancer populations, a recent systematic review and meta-analysis investigated digital health behavior-change interventions, which targeted diet and physical activity in cancer survivors [25]. The authors reported a mean improvement of 41 minutes per week of moderate-to-vigorous physical activity levels $(P=.006)$ and a pooled reduction in body mass index (BMI)/weight of -0.23
$(P=.011)$ with the use of digital interventions. However, technology-supported interventions may still require considerable facilitation by a health professional and use of clinical resources, inhibiting their practicality within usual care [26]. In the context of the growing demand for supportive health care in the cancer setting, technology-supported nutrition and physical activity interventions that are primarily self-guided have the potential to deliver broad-reaching interventions using minimal clinician resources. "Self-guided" refers to interventions delivered with minimal or no facilitation by a health professional and is a key component for improving sustainable dietary and physical activity behavior change. However, the efficacy of self-guided nutrition and physical activity interventions for people with cancer is yet to be established. This systematic review aims to describe and appraise the literature on the efficacy of technology-supported self-guided nutrition and physical activity interventions for people with cancer.

\section{Methods}

\section{Reporting Guidelines}

This systematic review was performed in accordance with the reporting requirements of the PRISMA statement [27]. The protocol was registered in the PROSPERO database with the reference number CRD42017080346 [28].

\section{Search Strategy}

The following databases were searched for peer-reviewed, English-language papers from 1973 to July 2018: Medline Complete, Scopus, CINAHL, EMBASE, Cochrane Library, and SPORTDiscus. The search terms included (Cancer OR oncology OR tumour OR malignancy OR malignant neoplasm) and (online OR internet OR "web-based" OR website OR ehealth OR app OR apps OR application OR mobile application OR smartphone OR mobile phone OR cell phone OR Mhealth OR telehealth OR telemedicine OR technology) and (nutrition OR diet OR physical activity OR exercise). Reference lists of relevant articles were manually searched to identify additional articles.

\section{Selection Criteria}

Studies were eligible for inclusion if they were original research studies on adult participants aged $\geq 18$ years who were diagnosed with any type of cancer at any stage prior to, during, or after cancer treatment, including cancer survivors, and received any treatment modality. Studies were included if they investigated a technology-supported nutrition and physical activity intervention that was largely self-guided and if the technology was accessed primarily outside the clinical setting. An intervention was deemed self-guided when there was minimal or no facilitation by a clinician. Minimal facilitation could encompass activities such as occasional email reminders, an introductory session on navigating the technology platform, or initial exercise prescription. Technology platforms for intervention delivery could be online, mobile phone, or tablet apps or wearable technology. The intervention content needed to focus on nutrition and physical activity. For the purpose of this paper, physical activity also includes exercise interventions. Interventions that included nutrition or physical activity as part 
of a broader suite of lifestyle or wellness interventions were excluded, unless nutrition or physical activity was a major component of the intervention, comprising at least a quarter of the content together. Studies were required to have a comparator group that could include active controls such as usual care, waitlist controls, or no treatment. Pilot studies that focused on feasibility and acceptability alone were excluded. Outcomes were any measures focused on health-related (eg, quality of life and fatigue), clinical (eg, weight and body composition), health service (eg, resource utilization, hospital admissions, and patient satisfaction), behavioral (eg, dietary intake and physical activity level), or financial outcomes (eg, cost to patients).

\section{Data Extraction and Quality Assessment}

Titles and abstracts were screened for eligibility by two independent reviewers (NK and $\mathrm{BB}$ ) to exclude articles that were clearly irrelevant. Full-text articles were retrieved and the selection criteria were applied independently by the same two reviewers. Any discrepancies were resolved by discussion.

Each included study was assessed for bias independently by the first author and one of the other authors using the Cochrane Risk of Bias tool [29]. Seven categories were examined to assess selection bias, performance bias, detection bias, attrition bias, reporting bias, and other sources of bias and rated as high risk, low risk, or unclear risk. Ratings were compared and a consensus was reached through discussion. As some of the categories were open to interpretation, all authors agreed on the following: (1) a rating of low risk for performance bias as the nature of these interventions indicated that blinding was not possible and the findings were not likely to be influenced by the lack of blinding, unless another reason was identified to rate otherwise and (2) in the absence of blinding, detection bias was rated as low risk if the outcomes were objectively assessed, and as high risk if outcomes were behavioral or patient reported. All studies were included regardless of the bias rating. The Behaviour Change Taxonomy by Michie et al (2013) was used to describe the type of behavior-change techniques reported within each included study [30]. The heterogeneity of studies and diversity of outcomes indicated that the quantitative synthesis of data was not appropriate.

\section{Results}

\section{Study Selection}

The literature search identified a total of 3346 articles, and eight more articles were identified from the reference lists of relevant papers. Of the total, 18 articles representing 16 studies were included in the systematic review. Two studies were reported in two separate papers each. One of these studies reported on different outcomes in separate papers [31,32]; the other study reported on outcomes at 6 months [33] and 12 months [34] in separate papers. All articles are included, but the findings are presented as a single study. Figure 1 describes the selection process.

\section{Overview of Included Studies}

Tables 1 and 2 present the characteristics of all included studies. All studies were randomized controlled trials presenting data from 2684 participants. The duration of follow-up ranged from 10 weeks to 12 months, and five studies reported follow-up duration of $\geq 6$ months. Comparator groups included waitlist controls in six studies [32,35-38], active controls in five studies [39-43], usual care in four studies [33,44-46], and no treatment controls in one study [47]. Three studies used more than one comparator group, one of which used two active controls [45], one used a no-treatment control and two active controls [46], and one used a waitlist control and an active control [37].

Figure 1. Selection process.

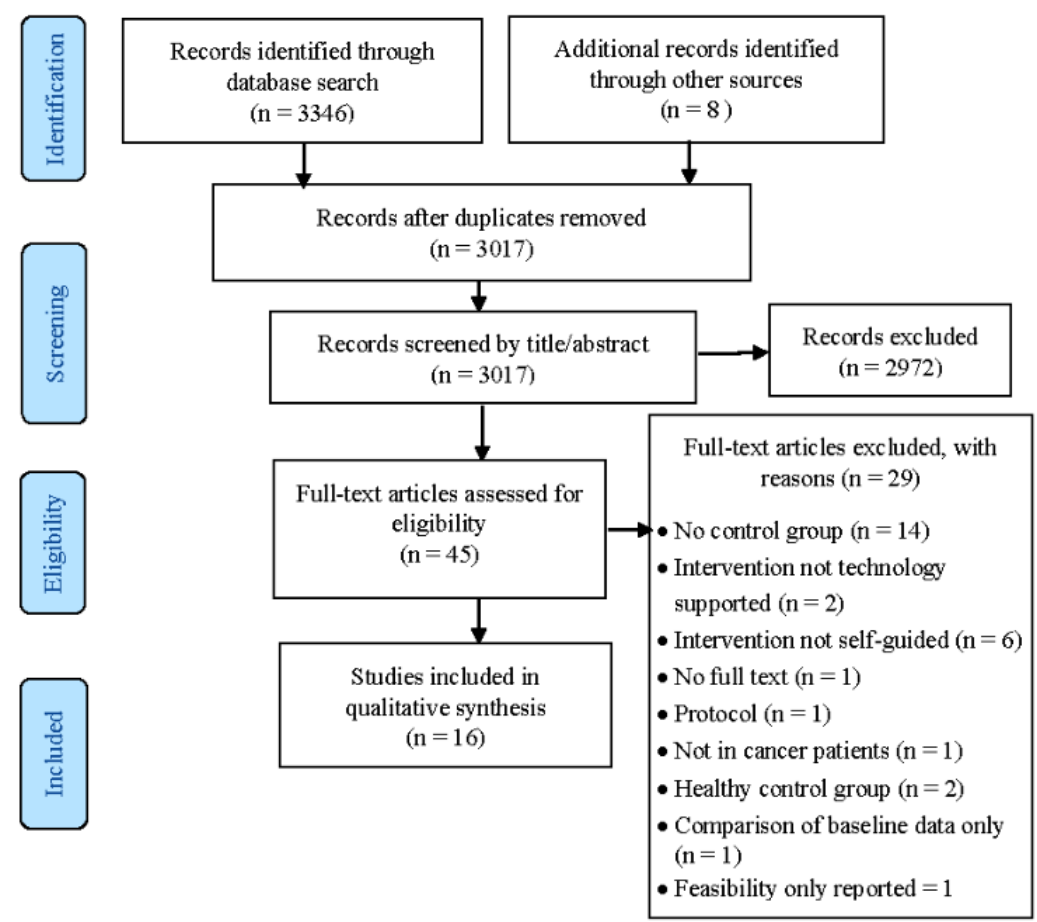


Table 1. Characteristics of the included studies.

\begin{tabular}{|c|c|c|c|c|c|c|}
\hline $\begin{array}{l}\text { Author, year, } \\
\text { country }\end{array}$ & Participants & Study design & Behavior-change technique $^{\mathrm{a}}$ & Self-guided component & Facilitated component & $\begin{array}{l}\text { Type of } \\
\text { control } \\
\text { group }\end{array}$ \\
\hline $\begin{array}{l}\text { Bantum et } \\
\text { al, 2014, } \\
\text { United } \\
\text { States [36] }\end{array}$ & $\begin{array}{l}\text { Cancer sur- } \\
\text { vivors between } \\
4 \text { wk and } 5 \mathrm{y} \\
\text { posttreatment } \\
\mathrm{N}=352 \\
\text { Consent } \\
\text { rate }=56 \% \\
\text { Retention } \\
\text { rate }=86 \%\end{array}$ & $\begin{array}{l}\text { Two-arm } \\
\text { RCT }^{\text {b }}\end{array}$ & $\begin{array}{l}\text { Goal setting (behavior) } \\
\text { Feedback on behavior } \\
\text { Self-monitoring of out- } \\
\text { come(s) of behavior } \\
\text { Social support (unspecified) } \\
\text { Instructions on how to per- } \\
\text { form a behavior } \\
\text { Social comparison } \\
\text { Credible source }\end{array}$ & $\begin{array}{l}\text { Six web-based modules of } \\
22 \text { topics, including healthy } \\
\text { eating, exercise, stress man- } \\
\text { agement, communication, } \\
\text { and fatigue management, } \\
\text { accessed over } 6 \text { weeks }\end{array}$ & $\begin{array}{l}\text { Baseline training of the } \\
\text { website content and weekly } \\
\text { goal setting of health behav- } \\
\text { ior change was discussed } \\
\text { with a facilitator on the } \\
\text { website }\end{array}$ & $\begin{array}{l}\text { Waitlist } \\
\text { control }\end{array}$ \\
\hline $\begin{array}{l}\text { Galiano- } \\
\text { Castillo et al, } \\
2016 \text { \& } \\
2017, \text { Spain } \\
{[31,32]}\end{array}$ & $\begin{array}{l}\text { Breast cancer } \\
\text { survivors } \\
\mathrm{N}=81 \\
\text { Consent } \\
\text { rate }=89 \% \\
\text { Retention } \\
\text { rate }=88 \%\end{array}$ & $\begin{array}{l}\text { Two-arm } \\
\text { RCT }\end{array}$ & $\begin{array}{l}\text { Feedback on behavior } \\
\text { Instructions on how to per- } \\
\text { form a behavior } \\
\text { Demonstration of the behav- } \\
\text { ior } \\
\text { Credible source }\end{array}$ & $\begin{array}{l}\text { Web-based } 8 \text {-week interven- } \\
\text { tion providing access to } 24 \\
\text { exercise sessions, } 3 \text { per } \\
\text { week, tailored to partici- } \\
\text { pants, including warm-up, } \\
\text { resistance and aerobic exer- } \\
\text { cise, and cool down to meet } \\
\text { The American College of } \\
\text { Sports Medicine recommen- } \\
\text { dations for cancer survivors }\end{array}$ & $\begin{array}{l}\text { Baseline familiarity with the } \\
\text { content to individualize the } \\
\text { exercise training. Instant } \\
\text { messages and video confer- } \\
\text { ence were available if re- } \\
\text { quested by the participant } \\
\text { for further exercise support }\end{array}$ & $\begin{array}{l}\text { Waitlist } \\
\text { control }\end{array}$ \\
\hline $\begin{array}{l}\text { Gnagarella } \\
\text { et al, 2016, } \\
\text { Italy [39] }\end{array}$ & $\begin{array}{l}\text { Any cancer diag- } \\
\text { nosis during or } \\
\text { after treatment } \\
\mathrm{N}=125 \\
\text { Consent } \\
\text { rate }=28 \% \\
\text { Retention } \\
\text { rate }=59 \%\end{array}$ & $\begin{array}{l}\text { Two-arm } \\
\text { RCT }\end{array}$ & $\begin{array}{l}\text { Instructions on how to per- } \\
\text { form a behavior } \\
\text { Information about health } \\
\text { consequences } \\
\text { Credible source }\end{array}$ & $\begin{array}{l}\text { Web-based 6-month inter- } \\
\text { vention with access to } \\
\text { weekly forums, blogs, and } \\
\text { content on healthy eating to } \\
\text { reduce treatment symptoms, } \\
\text { control weight loss, or } \\
\text { maintaining body mass and } \\
\text { guidelines for healthy eating }\end{array}$ & $\begin{array}{l}\text { Option to interact with facil- } \\
\text { itator upon request }\end{array}$ & $\begin{array}{l}\text { Active } \\
\text { control }\end{array}$ \\
\hline $\begin{array}{l}\text { Kanera et al, } \\
2016 \text { \& } \\
2017 \text {, } \\
\text { Netherlands } \\
{[33,34]}\end{array}$ & $\begin{array}{l}\text { Cancer sur- } \\
\text { vivors between } \\
4 \text { wk and } 56 \mathrm{wk} \\
\text { posttreatment } \\
\mathrm{N}=462 \\
\text { Consent } \\
\text { rate }=36 \% \\
\text { Retention } \\
\text { rate }=82.5 \%\end{array}$ & $\begin{array}{l}\text { Two-arm } \\
\text { RCT }\end{array}$ & $\begin{array}{l}\text { Goal setting (behavior) } \\
\text { Problem solving } \\
\text { Action planning } \\
\text { Discrepancy between cur- } \\
\text { rent behavior and goals } \\
\text { Feedback on behaviors } \\
\text { Self-monitoring of behaviors } \\
\text { Instructions on how to per- } \\
\text { form a behavior } \\
\text { Information about health } \\
\text { consequences } \\
\text { Social comparison } \\
\text { Credible source } \\
\text { Pros and cons }\end{array}$ & $\begin{array}{l}\text { Web-based intervention over } \\
6 \text { months with } 8 \text { modules of } \\
\text { videos, written content, goal } \\
\text { setting, action planning, and } \\
\text { problem identification in- } \\
\text { cluding nutrition, exercise, } \\
\text { smoking, fatigue, anxiety, } \\
\text { and depression }\end{array}$ & No facilitation & $\begin{array}{l}\text { Usual } \\
\text { care }\end{array}$ \\
\hline
\end{tabular}




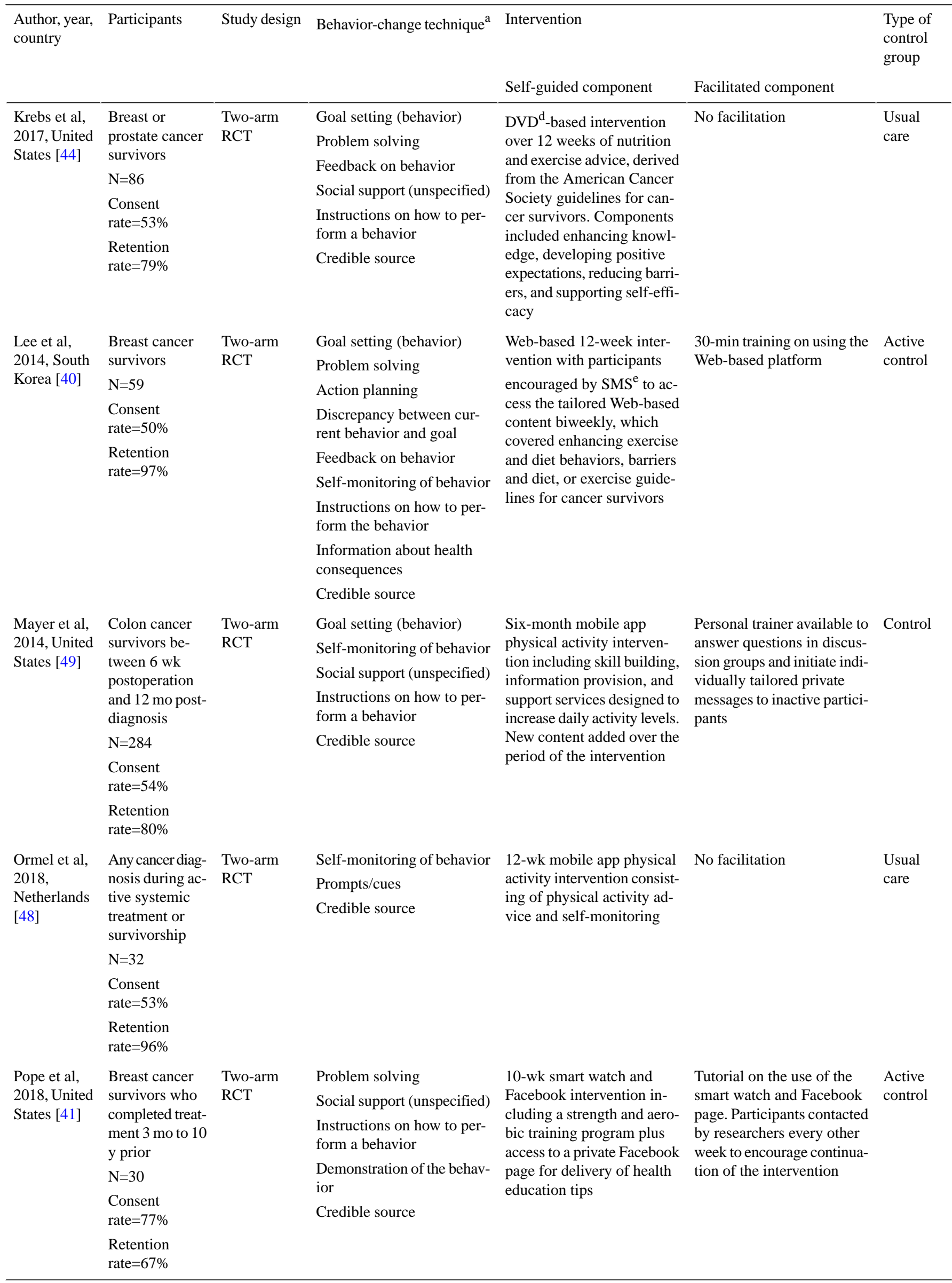




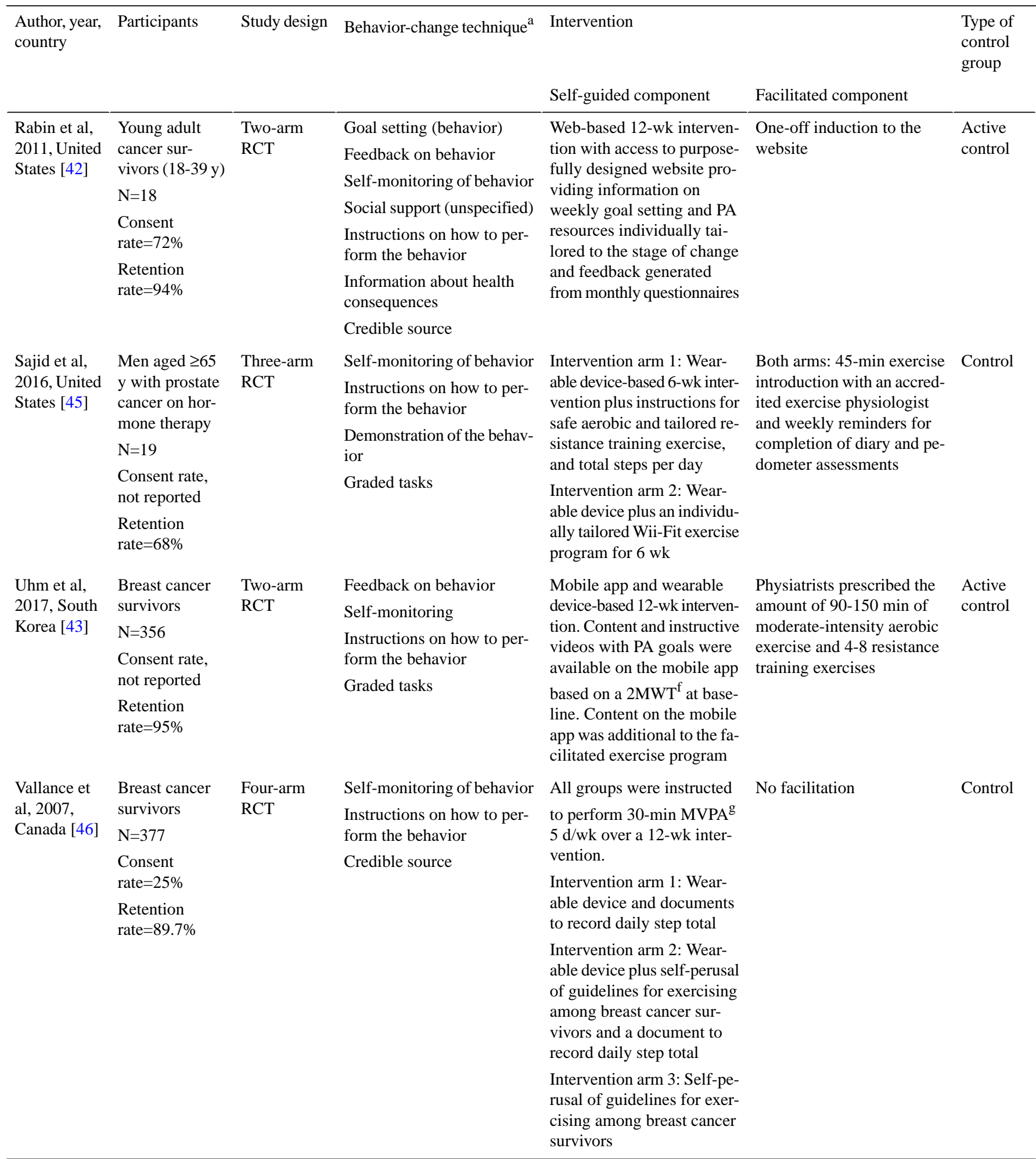




\begin{tabular}{|c|c|c|c|c|c|c|}
\hline \multirow{2}{*}{$\begin{array}{l}\text { Author, year, } \\
\text { country }\end{array}$} & \multirow[t]{2}{*}{ Participants } & \multirow[t]{2}{*}{ Study design } & \multirow{2}{*}{ Behavior-change technique $^{\mathrm{a}}$} & \multicolumn{2}{|l|}{ Intervention } & \multirow{2}{*}{$\begin{array}{l}\text { Type of } \\
\text { control } \\
\text { group }\end{array}$} \\
\hline & & & & Self-guided component & Facilitated component & \\
\hline \multirow{12}{*}{$\begin{array}{l}\text { Valle et al, } \\
\text { 2017, United } \\
\text { States [37] }\end{array}$} & \multirow{12}{*}{$\begin{array}{l}\text { Breast cancer } \\
\text { survivors } \\
\mathrm{N}=35 \\
\text { Consent } \\
\text { rate }=70 \% \\
\text { Retention } \\
\text { rate }=94 \%\end{array}$} & \multirow{12}{*}{$\begin{array}{l}\text { Three-arm } \\
\text { RCT }\end{array}$} & Goal setting (behavior) & \multirow{12}{*}{$\begin{array}{l}\text { Intervention arm 1: Web- } \\
\text { based with mobile compan- } \\
\text { ion app providing 24-wk in- } \\
\text { tervention on nutrition and } \\
\text { PA for body weight and } \\
\text { weekly email of standard- } \\
\text { ized content on behavior- } \\
\text { change strategies related to } \\
\text { weight loss. Web or mobile } \\
\text { app accessed to log body } \\
\text { weight and PA } \\
\text { Intervention arm } 2 \text { : Same as } \\
\text { intervention arm } 1 \text { plus a } \\
\text { wearable device and addi- } \\
\text { tional education on steps per } \\
\text { day and meeting the steps- } \\
\text { per-day recommendations }\end{array}$} & \multirow{12}{*}{$\begin{array}{l}\text { Both intervention arms: } 1 \text {-h } \\
\text { face-to-face nutrition con- } \\
\text { sult, } 24 \text { weekly emails of } \\
\text { behavior change to reach } \\
150-225 \text { min of moderate- } \\
\text { intensity PA and for energy } \\
\text { reduction by } 100 \text { kcal } \\
\text { through dietary intake, and } \\
\text { tailored feedback on weight } \\
\text { were provided }\end{array}$} & \multirow{12}{*}{$\begin{array}{l}\text { Waitlist } \\
\text { control }\end{array}$} \\
\hline & & & Problem solving & & & \\
\hline & & & Goal setting (outcome) & & & \\
\hline & & & Feedback on behavior & & & \\
\hline & & & Self-monitoring of behavior & & & \\
\hline & & & Monitoring of outcome(s) of & & & \\
\hline & & & behavior without feedback & & & \\
\hline & & & $\begin{array}{l}\text { Instructions on how to per- } \\
\text { form a behavior }\end{array}$ & & & \\
\hline & & & $\begin{array}{l}\text { Information about health } \\
\text { consequences }\end{array}$ & & & \\
\hline & & & Graded tasks & & & \\
\hline & & & Credible source & & & \\
\hline & & & Self-talk & & & \\
\hline \multirow[t]{4}{*}{$\begin{array}{l}\text { Yun et al, } \\
2012, \text { Korea } \\
{[38]}\end{array}$} & $\begin{array}{l}\text { Cancer sur- } \\
\text { vivors }<24 \text { mo } \\
\text { posttreatment }\end{array}$ & $\begin{array}{l}\text { Two-arm } \\
\text { RCT }\end{array}$ & $\begin{array}{l}\text { Monitoring outcome(s) of } \\
\text { behavior by others without } \\
\text { feedback }\end{array}$ & \multirow{4}{*}{$\begin{array}{l}\text { Web-based } 12 \text {-wk interven- } \\
\text { tion via seven education } \\
\text { modules with personally } \\
\text { tailored information on ener- } \\
\text { gy conservation, PA, nutri- } \\
\text { tion, sleep hygiene, pain, } \\
\text { distress management, and } \\
\text { information on fatigue }\end{array}$} & \multirow[t]{4}{*}{ No facilitation } & \multirow[t]{4}{*}{$\begin{array}{l}\text { Waitlist } \\
\text { control }\end{array}$} \\
\hline & $N=273$ & & Social support (unspecified) & & & \\
\hline & $\begin{array}{l}\text { Consent } \\
\text { rate }=28 \%\end{array}$ & & $\begin{array}{l}\text { Instructions on how to per- } \\
\text { form a behavior }\end{array}$ & & & \\
\hline & $\begin{array}{l}\text { Retention } \\
\text { rate }=89 \%\end{array}$ & & Credible source & & & \\
\hline
\end{tabular}

${ }^{\mathrm{a}}$ Determined from Michie et al [30].

${ }^{\mathrm{b}} \mathrm{RCT}$ : randomized controlled trial.

${ }^{\mathrm{c}}$ PA: physical activity.

${ }^{\mathrm{d}}$ DVD: digital video disk.

${ }^{\text {e }}$ SMS: short message service.

f 2 MWT: 2-minute walk test.

gMVPA: moderate-to-vigorous physical activity.

Sample sizes ranged from 18 to 462 participants. Thirteen studies included cancer survivors of a variety of cancer types, with a majority of breast or prostate cancer survivors [32,33,35-38,40-44,46,48]; one study included participants receiving active cancer treatment [45]; and two studies included participants who were at any cancer stage prior to, during, or after cancer treatment $[39,49]$.

Nine studies examined a physical activity intervention $[32,35,41-43,45,46,48,49]$, one study examined a nutrition intervention [39], and six studies examined a combined physical activity and nutrition intervention [33,36-38,40,44]. Of the studies that examined a combined intervention, three were part of a broader suite of interventions encompassing areas such as fatigue management, stress management, and pain; however, nutrition and physical activity were major components of these interventions [33,36,38].

Participation rates for the studies ranged from $25 \%$ to $89 \%$ (median $=53 \%$ ), and four studies reported a consent rate of $\geq 70 \%$. However, once enrolled in the studies, participant retention was generally high, with 12 of the 16 studies retaining
$>80 \%$ of participants over the study duration. Methods for measuring uptake and adherence to the intervention, including the proportion of patients who accessed the intervention content and the average number of logins to the intervention website, varied considerably, making comparison between studies challenging. Four studies did not report on uptake or intervention adherence [39,43,45,49].

Studies used between 3 and 11 (median=5.5) behavior-change techniques, and provision of instructions to perform a behavior was the most common technique used in all but one of the included studies. Other commonly used techniques included Credible Source to deliver information (14 studies), self-monitor behavior (11 studies), and provide feedback on behavior ( 9 studies). In some studies, insufficient description of the intervention prevented a full analysis of the behavior-change techniques employed $[38,39,46,49]$. Insufficient description of the intervention also limited the ability to assess the quality and content of the interventions. However, 14 of the included studies used a behavior change technique-Credible Source-meaning the content was provided by a source that was considered reliable. 
Table 2. Outcome measures and findings of the included studies.

\begin{tabular}{|c|c|c|c|}
\hline Author, year, country & Outcomes & Intervention uptake & Between-group findings \\
\hline \multirow[t]{2}{*}{$\begin{array}{l}\text { Bantum et al, 2014, } \\
\text { United States [36] }\end{array}$} & $\begin{array}{l}\text { Measured at baseline and } 6 \\
\text { mo }\end{array}$ & $\begin{array}{l}67 \% \text { participants accessed } \\
\text { all sessions. }\end{array}$ & \multirow{2}{*}{$\begin{array}{l}\text { Compared to control group, the intervention group showed a } \\
\text { significant improvement in insomnia ( } 9.6 \text { to } 10.1 \text { vs } 9.6 \text { to } 9.2 \text {; } \\
P=.03 \text { ), strenuous exercise ( } 29 \mathrm{~min} / \text { wk [no change] vs } 32 \text { to } 51 \\
\text { min/wk; } P=.01 \text { ), stretching ( } 26 \text { to } 25 \mathrm{~min} / \text { wk vs } 31 \text { to } 46 \\
\min / \mathrm{wk} ; P=.01 \text { ) }\end{array}$} \\
\hline & $\begin{array}{l}\text { Primary outcomes: fruit and } \\
\text { vegetable intake, } \mathrm{PA}^{\mathrm{a}}, \mathrm{de}- \\
\text { pression, fatigue, and insom- }\end{array}$ & $\begin{array}{l}\text { Mean number of sessions } \\
\text { accessed }=5.3(\text { SD 1.28) }\end{array}$ & \\
\hline
\end{tabular}

Forbes et al, 2015, Canada [35]

Galiano-Castillo et al, 2016 \& 2017, Spain $[31,32]$

Gnagarella et al, 2016, Italy [39]

Kanera et al, 2016 \& 2017, Netherlands $[33,34]$

Krebs et al, 2017, Unit- Measured at baseline and 12 ed States [44]

wk

Primary outcomes: fruit and vegetable intake and PA

Lee et al, 2014, South Korea [40]

Measured at baseline and 12 wk

Primary outcomes: diet composition and PA

Secondary outcomes: quality of life, anxiety, depression, fatigue, motivational readiness, and self-efficacy

Mayer et al, 2014, United States [49]

Ormel et al, 2018, Netherlands [48]
Measured at baseline and 3 , 6 , and 9 mo

Primary outcome: physical activity

Secondary outcomes: distress and quality of life

Measured at baseline, and 6 Not reported and $12 \mathrm{wk}$

Primary outcome: feasibility of the intervention $\mathrm{Sec}$ ondary outcome: PA
$67 \%$ viewed the modules at least once. Average number of logins over the 9 -wk period $=10.3$

Adherence rate $=93.9 \%$ of the scheduled sessions

Compared to the control group, at $8 \mathrm{wk}$, the intervention group showed improved isometric abdominal $(P<.001, d=1.02)$, back $(P<.001, d=1.31)$, lower-body $(P=.001, d=-0.81)$; and hand grip strength $(P=.006, d=0.66) ; 6 \mathrm{MWT}^{\mathrm{b}}(P<.001, d=0.92)$; global quality of life $(P<.001, d=0.89)$; physical functioning $(P<.001, d=0.9)$; role functioning $(P=.001, d=0.78)$; cognitive functioning $(P=.002, d=0.75)$; pain severity $(P=.001, d=-0.82)$; fatigue $(P<.001, d=-0.89)$; and pain interference $(P=.05$, $d=-0.47$ ). At 6 months, the intervention effect was maintained for all except role functioning and pain severity

No significant differences between groups for nutrition knowledge or food consumption. Compared to the control group, the intervention group had improved role functioning in the quality of life scale at 6 mo $(-6.3$ vs $5.1, P=.02)$

Average of 2.23 (SD 1.53) modules followed. PA activity module followed by $25 \%$ participants. Diet module followed by $62 \%$ participants

$72 \%$ viewed the $\mathrm{DVD}^{\mathrm{c}}, 50 \%$ completed the full DVD

$89 \%$ of patients consistently participated in the program throughout the intervention

Compared to control group, after $12 \mathrm{wk}$, the intervention group showed significantly improved proportion of participants meeting the recommendations of $150 \mathrm{~min} / \mathrm{wk}$ moderate-intensity exercise $(35.7 \%$ vs $65.5 \%, P<.0001)$ and five servings of fruit or vegetables/d (32.1\% vs $55.2 \%, P=.001)$ and improved the diet-quality index (9.6 vs $11.1, P=.001)$, physical functioning (75.9 vs $83.6, P=.02$ ), fatigue ( 15.3 vs $13.5, P=.03$ ), and selfefficacy for exercise $(P=.02)$ and fruit and vegetable intake $(P=.02)$

93.8\% participants described as users (accessed system at least once). Of the 180 days of possible use, mean use $=55.3$ days $($ SD 50.0)

No significant differences between the intervention and control groups

Compared to the control group, the intervention group had significantly increased total minutes of PA at $6 \mathrm{wk}(2348 \mathrm{~min} / \mathrm{wk}$ vs $3773 \mathrm{~min} / \mathrm{wk}, P=.04)$, but there was no difference in sedentary time between groups. There were no significant betweengroup differences at 12 weeks 


\begin{tabular}{ll}
\hline Author, year, country & Outcomes \\
\hline $\begin{array}{l}\text { Pope et al, 2018, United } \\
\text { States [41] }\end{array}$ & $\begin{array}{l}\text { Measured at baseline and 10 } \\
\text { wk } \\
\text { Primary outcomes: PA and } \\
\text { energy expenditure } \\
\text { Secondary outcomes: anthro- } \\
\text { pometry, body composition, } \\
\text { cardiorespiratory fitness, } \\
\text { quality of life, and psychoso- } \\
\text { cial constructs }\end{array}$
\end{tabular}

Rabin et al, 2011, Unit- $\quad$ Measured at baseline and 12 ed States [42]

wk

Primary outcomes: feasibili-

ty and acceptability

Secondary outcomes: PA, mood, and fatigue

Sajid et al, 2016, United Measured at baseline, $6 \mathrm{wk}$, Not reported States [45] and $12 \mathrm{wk}$

Primary outcome: physical performance

Secondary outcomes: steps per day, lean muscle mass, and chess press repetitions

Uhm et al, 2017, South Measured at baseline, $6 \mathrm{wk}$, Not reported Korea [43] and $12 \mathrm{wk}$

Primary outcomes: PA, quality of life, anthropometrical measures, body mass index, blood pressure, functional capacity, and hand grip strength

Vallance et al, 2007, Canada [46]

Measured at baseline and 12 wk

Primary outcomes: PA

Secondary outcomes: quality of life, fatigue, brisk walking, and objective step count

Valle et al, 2017, United States [37]
Intervention uptake

Participants wore the smatt watch 6-7 d/wk and accessed the Facebook page 1.2 times/wk on an average

Average number of website logins $=14.75($ SD 8.46) 12 wk

Compared to the control group, at 12 weeks, there was a medium effect of the intervention on increasing MVPA $^{d}$ (16.5 min/wk vs $102.5 \mathrm{~min} / \mathrm{wk}, d=0.64$ ) and a large effect of the intervention on mood $(-5.00 \mathrm{vs}-25.86, d>0.80)$ and fatigue $(-3.30 \mathrm{vs}$ $-11.43, d>0.80)$. However, these differences were not statistically significant

Compared to controls, intervention arm 1 showed greater improvement in physical performance $(P=.04)$ and a higher rate of change in steps per day at $12 \mathrm{wk}(P<.01)$. There were no additional between-group differences seen either between intervention arm 1 and control or intervention arm 2 and control

There were no significant between-group differences at 6 and

Compared to the control group, a significant improvement was seen in MVPA at $12 \mathrm{wk}$ in intervention arm $1(30 \mathrm{~min} / \mathrm{wk}$ vs $59 \mathrm{~min} / \mathrm{wk}, P=.02)$ and intervention $\operatorname{arm} 2(30 \mathrm{~min} / \mathrm{wk}$ vs 87 $\mathrm{min} / \mathrm{wk}, P=.02)$. Compared to the control group, significant improvements were seen in brisk walking at $12 \mathrm{wk}$ in intervention arm 1 ( $0 \mathrm{~min} / \mathrm{wk}$ vs $94 \mathrm{~min} / \mathrm{wk}, P<.001)$, intervention arm $2(0 \mathrm{~min} / \mathrm{wk}$ vs $58 \mathrm{~min} / \mathrm{wk}, P=.03)$, and intervention arm $3(0$ $\mathrm{min} / \mathrm{wk}$ vs $72 \mathrm{~min} / \mathrm{wk}, P=.006)$ were observed. No differences in objective step count. Intervention arm 2 showed significant improvement in quality of life (6.9 vs $1.1, P=.003)$ at $12 \mathrm{wk}$ compared to control

Intervention arm 2 significantly reduced body mass index $(-0.4$ vs $0.1, P=0.046$ ) compared to controls at 6 mo. Intervention arm 1 maintained $\mathrm{HBA}_{1 \mathrm{c}}{ }^{\mathrm{e}}$ levels as compared to increased $\mathrm{HBA}_{1 \mathrm{c}}$ levels observed in the control group ( 0.0 vs $\left.0.15, P=.02\right)$. No other significant between-group differences were observed
Secondary outcomes: PA, body mass index, weight, body composition, and metabolic syndrome biomarkers
Intervention arm 1: 100\% participants reported reading some/all/most of the email content and email feedback Intervention arm 2: $90 \%$ participants reported reading some/all/most of the email content and email feedback 


\begin{tabular}{llll}
\hline Author, year, country & Outcomes & Intervention uptake & Between-group findings \\
\hline $\begin{array}{l}\text { Yun et al, 2012, Korea } \\
{[38]}\end{array}$ & $\begin{array}{l}\text { Measured at baseline and } 12 \\
\text { wk }\end{array}$ & $\begin{array}{l}\text { Intervention completed by } \\
83.1 \% \text { participants }\end{array}$ & $\begin{array}{l}\text { Compared to the control group, the intervention group had a } \\
\text { significantly greater decrease in fatigue (group difference }=-0.66, \\
\end{array}$ \\
& $\begin{array}{l}\text { Primary outcome: fatigue } \\
\text { Secondary outcomes: nutri- } \\
\text { tional status, quality of life, } \\
\text { anxiety, and depression }\end{array}$ & $\begin{array}{l}P=.001, d=0.29) \text { and anxiety }(-0.9, P=.004, d=0.33) \text { and signif- } \\
\text { icantly greater increase in nutritional status }(0.47, P=.04, \\
d=0.23), \text { global quality of life }(5.22, P=.02, d=0.26), \text { emotional } \\
\text { functioning }(4.69, P=.02, d=0.19), \text { social functioning }(4.73, \\
P=.03, d=0.24), \text { and cognitive functioning }(6.09, P=.002,\end{array}$ \\
\end{tabular}

${ }^{\mathrm{a}} \mathrm{PA}$ : physical activity.

${ }^{\mathrm{b}} 6 \mathrm{MWT}$ : six minute walk test.

${ }^{\mathrm{c}}$ DVD: digital video disk.

dMVPA: moderate to vigorous physical activity.

${ }^{\mathrm{e}} \mathrm{HBA}_{1 \mathrm{c}}$ : hemoglobin $\mathrm{A}_{1 \mathrm{c}}$.

\section{Technology Platform and Level of Facilitation}

The majority of studies ( $n=9)$ were delivered as Web-based modules with content covering nutrition and physical activity recommendations [32,33,35-40,42]. Three studies used a wearable device to deliver a physical activity intervention $[41,45,46]$. The remaining studies used mobile apps $(n=3)$ or digital video disk $(n=1)$ to deliver content on nutrition and physical activity recommendations $[43,44,48,49]$. In five studies, there was no facilitation of the self-guided intervention $[33,38,44,46,49]$. In the remaining studies, facilitation involved baseline training on the intervention or Web platform $[32,36,37,40-43,45]$, emails sent at varying frequencies to provide content updates, reminders or summaries of completed physical activity $[35,37,45]$, and interaction with a facilitator in a discussion group or upon request $[39,48]$.

\section{Risk of Bias Assessment}

The outcome of the bias assessment is presented in Table 3. All included studies were randomized controlled trials. However, as evident from Table 3, there was a high degree of variation in the bias of the included studies, in particular, lack of clarity about the randomization process and few studies included blinding of the outcome assessment.

\section{Behavioral Outcomes}

Of the five studies that investigated dietary behaviors, two found improvements in the intervention arm. Kanera et al (2016) reported a significant increase in vegetable consumption after 6 months of use of a personalized web-based intervention, although this increase was not sustained at 12 months postintervention [33,34]. Similarly, Lee et al (2014) observed a significant improvement in diet quality and fruit and vegetable intake following a 12-week Web-based intervention, but did not measure longer-term outcomes [40].

One of the studies where no benefit of intervention was observed on dietary behavior did not specify the inclusion criteria for selecting participants who were not meeting the dietary recommendations [36]. The authors subsequently found they had recruited participants who had better-than-average fruit and vegetable intake and little need for health behavior change [36]. The two remaining studies that found no improvement in dietary behavior were not powered to detect between-group differences [39,44].

In total, 14 studies examined interventions to promote physical activity behaviors, of which eight studies reported positive outcomes. Bantum et al (2014) reported significant increases in both strenuous exercise and stretching at 6 months after a 6-week Web-based intervention including a suite of health behavior-change content [36]. Another 8-week Web-based intervention delivering physical activity recommendations tailored to participants found significant improvements in isometric abdominal, back, and lower-body muscle strength at 2 and 6 months following the intervention [32]. A 12-week mobile app intervention providing physical activity advice reported a significant improvement in the total minutes of physical activity at 6 weeks but no difference at 12 weeks [49].

Kanera et al (2016) found a significant increase in moderate physical activity levels after 6 months of use of a personalized Web-based intervention; however, similar to the effect on dietary behavior in this study, the difference was not sustained at 12 months $[33,34]$. In a 12 -week Web-based intervention providing tailored exercise content to participants, significant improvements were observed in the proportion of participants following moderate-intensity exercise recommendations [40]. Sajid et al (2016) found a higher rate of change in the number of steps per day among participants who received instructions for exercising and used a wearable device in combination as compared to the control group. However, the same effect was not observed when participants followed a tailored Wii-Fit exercise program in combination with the wearable device, although the sample size was small and not powered to detect differences [45]. In another study, participants using a wearable device alone or in combination with access to exercise guidelines experienced significant improvements in weekly moderate-to-vigorous intensity physical activity and brisk walking [46]. However, improvements in brisk walking were also observed in participants with access to exercise guidelines alone [46]. Although underpowered to detect a significant difference in moderate-to-vigorous physical activity levels, another study reported a medium effect (102.5 [intervention] vs 16.5 [control] minutes/week) of a Web-based intervention after 12 weeks [42]. 
Table 3. Risk of bias for included studies.

\begin{tabular}{|c|c|c|c|c|c|c|c|}
\hline Author, year & $\begin{array}{l}\text { Random sequence } \\
\text { generation }\end{array}$ & $\begin{array}{l}\text { Allocation } \\
\text { concealment }\end{array}$ & $\begin{array}{l}\text { Blinding of partici- } \\
\text { pants/personnel }\end{array}$ & $\begin{array}{l}\text { Blinding of out- } \\
\text { come assessment }\end{array}$ & $\begin{array}{l}\text { Incomplete out- } \\
\text { come data }\end{array}$ & $\begin{array}{l}\text { Selective } \\
\text { reporting }\end{array}$ & $\begin{array}{l}\text { Other } \\
\text { bias }\end{array}$ \\
\hline Bantum et al, 2014 [36] & Low & Unclear & Low & High & High & High & High \\
\hline Forbes et al, 2015 [35] & Low & Unclear & Low & Low & Low & Unclear & Low \\
\hline $\begin{array}{l}\text { Galiano-Castillo et al, } 2016 \\
\text { [31], } 2017 \text { [32] }\end{array}$ & Low & Unclear & Low & Low & Low & High & Low \\
\hline Gnagnarella et al, 2016 [39] & Low & Unclear & Low & High & High & High & High \\
\hline $\begin{array}{l}\text { Kanera et al, } 2016 \text { [33], } \\
2017 \text { [34] }\end{array}$ & Low & Low & High & Low & Low & Low & Low \\
\hline Krebs et al, 2017 [44] & Low & Low & Low & High & Low & Unclear & Low \\
\hline Lee et al, 2014 [40] & Low & Low & Low & High & Low & Low & Low \\
\hline Mayer et al, 2018 [49] & Unclear & Unclear & Low & High & Low & Unclear & Low \\
\hline Ormel et al, 2018 [48] & Low & Unclear & Low & High & Low & Low & Low \\
\hline Pope et al, 2018 [41] & Low & Unclear & High & Low & High & Unclear & Unclear \\
\hline Rabin et al, 2011 [42] & Unclear & Low & Low & High & High & Unclear & Unclear \\
\hline Sajid et al, 2016 [45] & Unclear & Low & Low & Unclear & Unclear & Unclear & High \\
\hline Uhm et al, 2017 [43] & High & Low & Low & High & High & Unclear & Low \\
\hline Vallance et al, 2007 [46] & Low & Low & Low & High & Low & High & Low \\
\hline Valle et al, 2017 [37] & Low & Low & Low & Low & Low & Low & Unclear \\
\hline Yun et al, 2012 [38] & Low & Low & Low & High & Low & Low & Unclear \\
\hline
\end{tabular}

Several studies that did not report positive outcomes had limitations. Although Forbes et al (2015) did not specifically select participants who did not meet the physical activity recommendations, a sub-group analysis showed that their Web-based intervention was more effective in participants who were not meeting the recommendations [35]. Similarly, another study failed to select participants with poor physical activity behaviors [41], and two studies were not powered to detect an effect $[37,44]$. Uhm et al used an active control group that received the same information as the intervention group but without the support of a mobile app [43]. Mayer et al (2018) considered the possibility that the lack of benefit was due to the short duration of the intervention [48]; however, the 6-month intervention was longer than that included in several studies reporting positive outcomes $[32,36,40,49]$.

Overall, technology-supported self-guided interventions appeared to have some benefit on dietary intake; however, the few studies that assessed this outcome had several limitations. A relatively consistent positive benefit was noted for physical activity, although the long-term benefits remain unknown; only one study reported outcomes beyond 6 months and found no effect at that time point. There were no patterns in the type or number of behavior-change techniques supporting the effective interventions in comparison to those for which no effect was observed. Effectiveness of interventions for physical activity level did not depend on whether physical activity was patient reported or objectively measured.

\section{Clinical Outcomes}

Clinical outcomes were reported in four of the included studies $[37,38,41,43]$. One study examined weight change, lean body mass, fat mass, BMI, and metabolic syndrome biomarkers after 6 months of use of a Web- and mobile app-based nutrition and physical activity intervention [37]. The intervention was tested in two groups: one used the intervention alone and other used the intervention along with wearable technology. The results showed an improvement in the BMI in the latter intervention group as compared to the control group. However, only the group that used the intervention alone showed an improvement in metabolic syndrome biomarkers [37]. Another study using a mobile app intervention and wearable device showed no difference in BMI, arm circumference, handgrip strength, and blood pressure between the intervention group and an active control group that received written information [43]. A further study reported a significant improvement in the nutritional status, measured using the Mini Nutrition Assessment tool, at 12 weeks after the use of a combined Web-based nutrition and physical activity intervention [38]. Pope et al (2018) found no differences in weight or body composition using a 10-week smart watch and Facebook physical activity intervention [41].

Overall, changes in clinical outcomes as a result of technology-supported self-guided interventions were inconsistent but were assessed in only a small number of studies, making it difficult to draw any concrete conclusions.

\section{Health-Related Outcomes}

HRQoL was assessed in nine studies, five of which used the European Organisation for Research and Treatment of Cancer Quality of Life Questionnaire - Core 30 [32,38-40,43], three used the Functional Assessment of Cancer Therapies questionnaire $[35,38,48]$, and one used the Patient-Reported Outcome Measurement System [41]. Two studies reported 
improved global HRQoL [32,38], and four studies reported improvements in one or more of the HRQoL subscales [32,38-40]. Studies demonstrating the most-beneficial HRQoL outcomes tended to be Web-based, used waitlist controls, involved a physical activity intervention, and reported very high adherence to the intervention. A further three-arm randomized trial by Sajid et al (2016) investigating functional capacity alone through use of a short physical performance battery reported improved physical performance in the wearable device intervention group compared to the control group, but this result was not observed for the wearable device plus Wii Fit arm [45].

Fatigue was measured in six studies, three of which used the Brief fatigue Inventory [36,38,40] and the remaining studies used the Piper Fatigue Scale [32], the fatigue scale from the Functional Assessment of Cancer Therapy-Anemia measurement system [46], and the Profile of Mood States scale [42]. Of the six studies, four reported significantly improved fatigue following the intervention $[32,38,40,42]$. Of the four studies, one study involved a 12-week Web-based intervention with modules covering sleep, hygiene, pain, distress management, and fatigue in addition to nutrition and physical activity. As such, the positive effect on fatigue may have been related to other components of the intervention. Two of the six studies found no significant difference in fatigue $[36,46]$. No consistent differences were evident between the studies that did and did not observe an effect on fatigue.

Yun et al (2012) observed a significantly greater decrease in anxiety, but not depression, after their 12-week Web-based intervention. However, similar to the effect on fatigue, the effect on anxiety may have been related to other components of the intervention beyond nutrition and physical activity [38]. Four studies on physical activity or combined nutrition and physical activity interventions measured depression [36,40], anxiety [40], distress [48], or mood disturbance [42], and found no significant between-group differences.

One study assessed the effect of a Web-based intervention of modules covering nutrition, exercise, stress management, communication, and fatigue management on insomnia and found a significant improvement following the 6-week intervention [36]. One study reported significant improvement in pain severity after an 8-week Web-based physical activity intervention as compared to the control arm [32].

Overall, HRQoL and fatigue appeared to improve after technology-supported self-guided interventions, and the majority of studies showed a positive benefit. The effects on mental health, pain, and insomnia require further investigation.

No studies investigated health service use or financial outcomes. In addition, no studies examined or compared outcomes according to key potential moderating factors such as gender, socioeconomic position, or ethnicity. Studies including only female patients with breast cancer were as likely to report positive outcomes as those including both male and female participants.

\section{Discussion}

The main finding of this review was that technology-supported self-guided interventions appear to improve physical activity behaviors and fatigue in people with cancer in the short term. Although many studies only measured these outcomes in the short term, a few studies that assessed these outcomes in the longer term found that this benefit was not sustained. There was a minor effect of such interventions on dietary behavior and an inconsistent effect on clinical outcomes such as weight, BMI, body composition parameters, and mental health outcomes. This finding is largely consistent with that of previous systematic reviews investigating digital health or eHealth interventions in cancer survivors, without focusing on the self-guided component [25]. For instance, Roberts et al (2017) reported improved physical activity and BMI in cancer survivors through digital health physical activity and diet interventions [25]. Similarly, Haberlin et al (2018) observed improvement in physical activity following the use of eHealth to promote physical activity among cancer survivors [50]. Both these reviews concluded that the effect of these interventions was promising, but studies using objective measures and assessing the impact on long-term outcomes remain a priority. Similar conclusions were drawn in a systematic review of computer-tailored physical activity and dietary behavior-promotion programs in the general population; this review showed improvements in physical activity and dietary behavior, but these improvements were limited to the short or medium term due to the lack of long-term follow-up in studies [23].

Inconsistent reporting of self-guided interventions is an issue that has resulted in a recent recommendation for the development of a standardized reporting framework for these types of interventions in people with cancer [51]. Overall, self-guided interventions are not well described in the literature, which limits definitive extraction of the key components of the intervention associated with improved health outcomes in people with cancer. In particular, this affected the extraction of the behavior-change techniques used within the interventions, and in some studies, sufficient information was not reported to determine the specific strategies used. A further issue was the reporting of intervention compliance, which was measured in different ways across studies and at times, not reported at all. Therefore, in cases where interventions did not report positive outcomes, it was difficult to determine whether the intervention itself was not effective or whether the lack of effect was related to poor compliance or insufficient participant engagement in the intervention. Similar issues were identified in a 2017 systematic review on self-guided interventions for psychosocial distress in people with cancer [26]. Of note, in 2011, a CONSORT checklist was published to improve the reporting of Web-based and mobile health interventions [52]; however, none of the studies in this systematic review reported the use of this framework.

Two of the studies included in this review did not specifically select participants who had poor health behaviors for the study. However, in their dietary and physical activity intervention group, Bantum et al (2014) found that they had recruited participants who had a better-than-average fruit and vegetable 
intake, and thus, there was no need to change their dietary behavior, potentially explaining the lack of effect of the intervention [36]. Similarly, Forbes et al (2015) did not target recruitment to participants who were not meeting physical activity recommendations; however, a subsequent subanalysis revealed that the intervention was more effective in participants who did not meet the physical activity recommendations at baseline [35]. Although only two studies in our review discussed this limitation, the eligibility criteria of the included studies revealed that 10 of the 16 studies did not specifically target participants with poor dietary or physical activity behaviors. Failure to specifically recruit participants requiring supportive care interventions has also been identified as an issue in several previous systematic reviews of supportive care interventions in cancer [26,53]. It is imperative that future research in this area targets people who require support but are currently not able to access the care they require.

Technology-supported self-guided interventions require a high level of self-motivation for participants to engage with the intervention. Compliance, or intervention uptake, provides some indication of participant engagement. However, inconsistencies in how the engagement was reported, as previously discussed, lead to difficulties in comparing studies. Although measured post-intervention, and therefore, not a true indicator of engagement with the intervention, patient satisfaction provides some insight into the acceptability of an intervention, which has implications for adherence and engagement [54]. A number of the studies included in this review measured patient satisfaction using a questionnaire or interview. Although patient satisfaction was high, there was no consistent approach or questionnaire used across studies; as such, comparison between studies was not possible.

Of the 16 studies included in this review, only two involved patients who were undergoing active cancer treatment. Personalized nutrition and physical activity interventions delivered individually by a clinician or other health professionals during cancer treatment have demonstrated benefits on body composition, nutritional status, quality of life, fatigue, and functional outcomes $[4,5,20,55]$. However, considering the increasing incidence of cancer, a personalized approach to nutrition and physical activity interventions may have limited long-term feasibility. Models for stratifying patients by risk categories are proposed for the management of cancer survivors [56] and may need to be considered for interventions delivered during active treatment. The level of facilitation in the studies included in this review was minimal, making this a potential cost-effective approach, although evaluation of the cost effectiveness was not a feature of any of the studies and resource requirements were not reported.

The strengths of this review are reporting according to the PRISMA guidelines; inclusion of risk of bias assessment; and categorization of the behavior change techniques underpinning the interventions, which has not been included in previous systematic reviews. Limitations include substantial heterogeneity among the included studies in terms of sample size, risk of bias, outcome measures, type and duration of interventions, and use of behavior-change techniques, which restricted our ability to distinguish the components of the interventions that were effective and to complete our meta-analyses.

In summary, this systematic review identified a short-term benefit of technology-supported self-guided interventions with regard to physical activity behavior and fatigue and a small benefit with regard to dietary behavior and HRQoL in people with cancer. However, there was considerable heterogeneity in the quality of the included studies and some heterogeneity along with major methodological limitations, which make interpretation of the findings challenging. Despite the potential of technology-supported interventions, there is a lack of evidence for their long-term benefit, which requires further investigation. Furthermore, a high proportion of studies did not actively target people with poor nutrition or physical activity behaviors. Future studies should ensure that interventions are tested in people requiring improvements in nutrition and physical activity who are not currently able to access the care they require.

\section{Acknowledgments}

This research did not receive any specific grant from funding agencies in the public, commercial, or not-for-profit sectors. AU is supported by a Victorian Cancer Agency Early Career Seed Grant. CG is supported by a Victorian Cancer Agency Clinical Research Fellowship.

\section{Conflicts of Interest}

None declared.

\section{References}

1. International Agency for Research on Cancer Globocan Database. Estimated Incidence, Mortality and Prevalence Worldwide in 2012 Fact Sheet URL: http://gco.iarc.fr/today/fact-sheets-cancers [accessed 2018-12-05] [WebCite Cache ID 74S7qoR18]

2. Miller KD, Siegel RL, Lin CC, Mariotto AB, Kramer JL, Rowland JH, et al. Cancer treatment and survivorship statistics, 2016. CA Cancer J Clin 2016 Jul;66(4):271-289 [FREE Full text] [doi: 10.3322/caac.21349] [Medline: 27253694]

3. Kushi LH, Doyle C, McCullough M, Rock CL, Demark-Wahnefried W, Bandera EV, American Cancer Society 2010 Nutrition and Physical Activity Guidelines Advisory Committee. American Cancer Society Guidelines on nutrition and physical activity for cancer prevention: reducing the risk of cancer with healthy food choices and physical activity. CA Cancer J Clin 2012;62(1):30-67 [FREE Full text] [doi: 10.3322/caac.20140] [Medline: 22237782] 
4. Arends J, Bachmann P, Baracos V, Barthelemy N, Bertz H, Bozzetti F, et al. ESPEN guidelines on nutrition in cancer patients. Clin Nutr 2017 Dec;36(1):11-48. [doi: 10.1016/j.clnu.2016.07.015] [Medline: 27637832]

5. Isenring E, Zabel R, Bannister M, Brown T, Findlay M, Kiss N. Updated evidence-based practice guidelines for the nutritional management of patients receiving radiation therapy and/or chemotherapy. Nutr Diet 2013;70(4):2013-2024. [doi: $10.1111 / 1747-0080.1]$

6. Marshall KM, Loeliger J, Nolte L, Kelaart A, Kiss NK. Prevalence of malnutrition and impact on clinical outcomes in cancer services: A comparison of two time points. Clin Nutr 2018 May 02. [doi: 10.1016/j.clnu.2018.04.007] [Medline: 29789167]

7. Blauwhoff-Buskermolen S, Versteeg KS, de van der Schueren MAE, den Braver NR, Berkhof J, Langius JAE, et al. Loss of Muscle Mass During Chemotherapy Is Predictive for Poor Survival of Patients With Metastatic Colorectal Cancer. J Clin Oncol 2016 Apr 20;34(12):1339-1344. [doi: 10.1200/JCO.2015.63.6043] [Medline: 26903572]

8. Martin L, Birdsell L, Macdonald N, Reiman T, Clandinin MT, McCargar LJ, et al. Cancer cachexia in the age of obesity: skeletal muscle depletion is a powerful prognostic factor, independent of body mass index. J Clin Oncol 2013 Apr 20;31(12):1539-1547. [doi: 10.1200/JCO.2012.45.2722] [Medline: 23530101]

9. Prado CMM, Baracos VE, McCargar LJ, Reiman T, Mourtzakis M, Tonkin K, et al. Sarcopenia as a determinant of chemotherapy toxicity and time to tumor progression in metastatic breast cancer patients receiving capecitabine treatment. Clin Cancer Res 2009 Apr 15;15(8):2920-2926 [FREE Full text] [doi: 10.1158/1078-0432.CCR-08-2242] [Medline: 19351764]

10. Cormie P, Zopf EM, Zhang X, Schmitz KH. The Impact of Exercise on Cancer Mortality, Recurrence, and Treatment-Related Adverse Effects. Epidemiol Rev 2017 Jan 01;39(1):71-92. [doi: 10.1093/epirev/mxx007] [Medline: 28453622]

11. Gardner JR, Livingston PM, Fraser SF. Effects of exercise on treatment-related adverse effects for patients with prostate cancer receiving androgen-deprivation therapy: a systematic review. J Clin Oncol 2014 Feb 01;32(4):335-346. [doi: 10.1200/JCO.2013.49.5523] [Medline: 24344218]

12. Furness K, Silvers MA, Savva J, Huggins CE, Truby H, Haines T. Long-term follow-up of the potential benefits of early nutritional intervention in adults with upper gastrointestinal cancer: a pilot randomised trial. Support Care Cancer 2017 Dec;25(11):3587-3593. [doi: 10.1007/s00520-017-3789-2] [Medline: 28612158]

13. Ravasco P, Monteiro-Grillo I, Camilo M. Individualized nutrition intervention is of major benefit to colorectal cancer patients: long-term follow-up of a randomized controlled trial of nutritional therapy. Am J Clin Nutr 2012 Dec;96(6):1346-1353. [doi: 10.3945/ajcn.111.018838] [Medline: 23134880]

14. Arem H, Chlebowski R, Stefanick ML, Anderson G, Wactawski-Wende J, Sims S, et al. Body mass index, physical activity, and survival after endometrial cancer diagnosis: results from the Women's Health Initiative. Gynecol Oncol 2013 Feb;128(2):181-186 [FREE Full text] [doi: 10.1016/j.ygyno.2012.10.029] [Medline: 23127972]

15. Arem H, Irwin ML. Obesity and endometrial cancer survival: a systematic review. Int J Obes (Lond) 2013 May;37(5):634-639 [FREE Full text] [doi: 10.1038/ijo.2012.94] [Medline: 22710929]

16. Blanchard CM, Courneya KS, Stein K, American Cancer Society's SCS-II. Cancer survivors' adherence to lifestyle behavior recommendations and associations with health-related quality of life: results from the American Cancer Society's SCS-II. J Clin Oncol 2008 May 1;26(13):2198-2204 [FREE Full text] [doi: 10.1200/JCO.2007.14.6217] [Medline: 18445845]

17. Chan DSM, Vieira AR, Aune D, Bandera EV, Greenwood DC, McTiernan A, et al. Body mass index and survival in women with breast cancer-systematic literature review and meta-analysis of 82 follow-up studies. Ann Oncol 2014 Oct;25(10):1901-1914 [FREE Full text] [doi: 10.1093/annonc/mdu042] [Medline: 24769692]

18. Nagle CM, Dixon SC, Jensen A, Kjaer SK, Modugno F, deFazio A, Australian Ovarian Cancer Study Group, Ovarian Cancer Association Consortium. Obesity and survival among women with ovarian cancer: results from the Ovarian Cancer Association Consortium. Br J Cancer 2015 Sep 01;113(5):817-826 [FREE Full text] [doi: 10.1038/bjc.2015.245] [Medline: 26151456]

19. Protani MM, Nagle CM, Webb PM. Obesity and ovarian cancer survival: a systematic review and meta-analysis. Cancer Prev Res (Phila) 2012 Jul;5(7):901-910 [FREE Full text] [doi: 10.1158/1940-6207.CAPR-12-0048] [Medline: 22609763]

20. O'Neill RF, Haseen F, Murray LJ, O'Sullivan JM, Cantwell MM. A randomised controlled trial to evaluate the efficacy of a 6-month dietary and physical activity intervention for patients receiving androgen deprivation therapy for prostate cancer. J Cancer Surviv 2015 Sep;9(3):431-440. [doi: 10.1007/s11764-014-0417-8] [Medline: 25916660]

21. Reeves MM, Terranova CO, Eakin EG, Demark-Wahnefried W. Weight loss intervention trials in women with breast cancer: a systematic review. Obes Rev 2014 Sep;15(9):749-768. [doi: 10.1111/obr.12190] [Medline: 24891269]

22. Bort-Roig J, Gilson ND, Puig-Ribera A, Contreras RS, Trost SG. Measuring and influencing physical activity with smartphone technology: a systematic review. Sports Med 2014 May;44(5):671-686. [doi: 10.1007/s40279-014-0142-5] [Medline: 24497157]

23. Broekhuizen K, Kroeze W, van Poppel MN, Oenema A, Brug J. A systematic review of randomized controlled trials on the effectiveness of computer-tailored physical activity and dietary behavior promotion programs: an update. Ann Behav Med 2012 Oct;44(2):259-286 [FREE Full text] [doi: 10.1007/s12160-012-9384-3] [Medline: 22767052]

24. Fanning J, Mullen SP, McAuley E. Increasing physical activity with mobile devices: a meta-analysis. J Med Internet Res 2012;14(6):e161 [FREE Full text] [doi: 10.2196/jmir.2171] [Medline: 23171838] 
25. Roberts AL, Fisher A, Smith L, Heinrich M, Potts HWW. Digital health behaviour change interventions targeting physical activity and diet in cancer survivors: a systematic review and meta-analysis. J Cancer Surviv 2017 Dec;11(6):704-719 [FREE Full text] [doi: $10.1007 / \mathrm{s} 11764-017-0632-1]$ [Medline: 28779220 ]

26. Ugalde A, Haynes K, Boltong A, White V, Krishnasamy M, Schofield P, et al. Self-guided interventions for managing psychological distress in people with cancer - A systematic review. Patient Educ Couns 2017 May;100(5):846-857 [FREE Full text] [doi: 10.1016/j.pec.2016.12.009] [Medline: 28081937]

27. Moher D, Liberati A, Tetzlaff J, Altman DG. Preferred reporting items for systematic reviews and meta-analyses: the PRISMA statement. BMJ 2009;339:b2535 [FREE Full text] [Medline: 19622551]

28. PROSPERO International prospective register of systematic reviews. Technology supported self-guided nutrition and physical activity interventions in adults with cancer URL: https://www.crd.york.ac.uk/prospero/display_record. php?RecordID=80346 [accessed 2018-12-12] [WebCite Cache ID 74c9B7Jff]

29. Cochrane Training. Cochrane handbook for systematic reviews of interventions, URL: https://training.cochrane.org/handbook [accessed 2018-12-05] [WebCite Cache ID 74S8TkJuD]

30. Michie S, Richardson M, Johnston M, Abraham C, Francis J, Hardeman W, et al. The behavior change technique taxonomy (v1) of 93 hierarchically clustered techniques: building an international consensus for the reporting of behavior change interventions. Ann Behav Med 2013 Aug;46(1):81-95. [doi: 10.1007/s12160-013-9486-6] [Medline: 23512568]

31. Galiano-Castillo N, Arroyo-Morales M, Lozano-Lozano M, Fernández-Lao C, Martín-Martín L, Del-Moral-Ávila R, et al. Effect of an Internet-based telehealth system on functional capacity and cognition in breast cancer survivors: a secondary analysis of a randomized controlled trial. Support Care Cancer 2017 Dec;25(11):3551-3559. [doi: 10.1007/s00520-017-3782-9] [Medline: 28639097]

32. Galiano-Castillo N, Cantarero-Villanueva I, Fernández-Lao C, Ariza-García A, Díaz-Rodríguez L, Del-Moral-Ávila R, et al. Telehealth system: A randomized controlled trial evaluating the impact of an internet-based exercise intervention on quality of life, pain, muscle strength, and fatigue in breast cancer survivors. Cancer 2016 Oct 15;122(20):3166-3174 [FREE Full text] [doi: 10.1002/cncr.30172] [Medline: 27332968]

33. Kanera IM, Bolman CAW, Willems RA, Mesters I, Lechner L. Lifestyle-related effects of the web-based Kanker Nazorg Wijzer (Cancer Aftercare Guide) intervention for cancer survivors: a randomized controlled trial. J Cancer Surviv 2016 Mar 17. [doi: 10.1007/s11764-016-0535-6] [Medline: 26984534]

34. Kanera IM, Willems RA, Bolman CAW, Mesters I, Verboon P, Lechner L. Long-term effects of a web-based cancer aftercare intervention on moderate physical activity and vegetable consumption among early cancer survivors: a randomized controlled trial. Int J Behav Nutr Phys Act 2017 Feb 10;14(1):19 [FREE Full text] [doi: 10.1186/s12966-017-0474-2] [Medline: 28187725]

35. Forbes CC, Blanchard CM, Mummery WK, Courneya KS. Feasibility and Preliminary Efficacy of an Online Intervention to Increase Physical Activity in Nova Scotian Cancer Survivors: A Randomized Controlled Trial. JMIR Cancer 2015 Nov 23;1(2):e12 [FREE Full text] [doi: 10.2196/cancer.4586] [Medline: 28410166]

36. Bantum EO, Albright CL, White KK, Berenberg JL, Layi G, Ritter PL, et al. Surviving and thriving with cancer using a Web-based health behavior change intervention: randomized controlled trial. J Med Internet Res 2014;16(2):e54 [FREE Full text] [doi: 10.2196/jmir.3020] [Medline: 24566820]

37. Valle CG, Deal AM, Tate DF. Preventing weight gain in African American breast cancer survivors using smart scales and activity trackers: a randomized controlled pilot study. J Cancer Surviv 2017 Feb;11(1):133-148. [doi: 10.1007/s11764-016-0571-2] [Medline: 27631874]

38. Yun YH, Lee KS, Kim Y, Park SY, Lee ES, Noh D, et al. Web-based tailored education program for disease-free cancer survivors with cancer-related fatigue: a randomized controlled trial. J Clin Oncol 2012 Apr 20;30(12):1296-1303 [FREE Full text] [doi: 10.1200/JCO.2011.37.2979] [Medline: 22412149]

39. Gnagnarella P, Misotti AM, Santoro L, Akoumianakis D, Del CL, De LF, et al. Nutritional Online Information for Cancer Patients: a Randomized Trial of an Internet Communication Plus Social Media Intervention. J Cancer Educ 2016 Dec;31(3):472-480. [doi: 10.1007/s13187-015-0820-5] [Medline: 25820605]

40. Lee MK, Yun YH, Park H, Lee ES, Jung KH, Noh D. A Web-based self-management exercise and diet intervention for breast cancer survivors: pilot randomized controlled trial. Int J Nurs Stud 2014 Dec;51(12):1557-1567. [doi: 10.1016/j.ijnurstu.2014.04.012] [Medline: 24856854]

41. Pope ZC, Zeng N, Zhang R, Lee HY, Gao Z. Effectiveness of Combined Smartwatch and Social Media Intervention on Breast Cancer Survivor Health Outcomes: A 10-Week Pilot Randomized Trial. J Clin Med 2018 Jun 07;7(6) [FREE Full text] [doi: 10.3390/jcm7060140] [Medline: 29880779]

42. Rabin C, Dunsiger S, Ness KK, Marcus BH. Internet-Based Physical Activity Intervention Targeting Young Adult Cancer Survivors. J Adolesc Young Adult Oncol 2011 Dec;1(4):188-194 [FREE Full text] [doi: 10.1089/jayao.2011.0040] [Medline: 23610737]

43. Uhm KE, Yoo JS, Chung SH, Lee JD, Lee I, Kim JI, et al. Effects of exercise intervention in breast cancer patients: is mobile health (mHealth) with pedometer more effective than conventional program using brochure? Breast Cancer Res Treat 2017 Feb;161(3):443-452. [doi: 10.1007/s10549-016-4065-8] [Medline: 27933450] 
44. Krebs P, Shtaynberger J, McCabe M, Iocolano M, Williams K, Shuk E, et al. An eHealth Intervention to Increase Physical Activity and Healthy Eating in Older Adult Cancer Survivors: Summative Evaluation Results. JMIR Cancer 2017 Mar 01;3(1):e4 [FREE Full text] [doi: 10.2196/cancer.6435] [Medline: 28410171]

45. Sajid S, Dale W, Mustian K, Kotwal A, Heckler C, Porto M, et al. Novel physical activity interventions for older patients with prostate cancer on hormone therapy: A pilot randomized study. J Geriatr Oncol 2016 Mar;7(2):71-80 [FREE Full text] [doi: 10.1016/j.jgo.2016.02.002] [Medline: 26916611]

46. Vallance JKH, Courneya KS, Plotnikoff RC, Yasui Y, Mackey JR. Randomized controlled trial of the effects of print materials and step pedometers on physical activity and quality of life in breast cancer survivors. J Clin Oncol 2007 Jun 10;25(17):2352-2359 [FREE Full text] [doi: 10.1200/JCO.2006.07.9988] [Medline: 17557948 ]

47. Hatchett A, Hallam JS, Ford MA. Evaluation of a social cognitive theory-based email intervention designed to influence the physical activity of survivors of breast cancer. Psychooncology 2013 Apr;22(4):829-836. [doi: 10.1002/pon.3082] [Medline: 22573338]

48. Mayer DK, Landucci G, Awoyinka L, Atwood AK, Carmack CL, Demark-Wahnefried W, et al. SurvivorCHESS to increase physical activity in colon cancer survivors: can we get them moving? J Cancer Surviv 2018 Feb;12(1):82-94. [doi: 10.1007/s11764-017-0647-7] [Medline: 28994035]

49. Ormel HL, van der Schoot GGF, Westerink NL, Sluiter WJ, Gietema JA, Walenkamp AME. Self-monitoring physical activity with a smartphone application in cancer patients: a randomized feasibility study (SMART-trial). Support Care Cancer 2018 May 21. [doi: 10.1007/s00520-018-4263-5] [Medline: 29785635]

50. Haberlin C, O'Dwyer T, Mockler D, Moran J, O'Donnell DM, Broderick J. The use of eHealth to promote physical activity in cancer survivors: a systematic review. Support Care Cancer 2018 Jun 16. [doi: 10.1007/s00520-018-4305-z] [Medline: 29909476]

51. Ugalde A, Kiss N, Livingston P, Aranda S. Towards a framework for reporting self-guided interventions for people with cancer. Current Opinion in Supportive and Palliative Care 2018:1. [doi: 10.1097/spc.0000000000000353]

52. Eysenbach G, CONSORT-EHEALTH Group. CONSORT-EHEALTH: improving and standardizing evaluation reports of Web-based and mobile health interventions. J Med Internet Res 2011;13(4):e126 [FREE Full text] [doi: 10.2196/jmir.1923] [Medline: 22209829]

53. Sanjida S, McPhail SM, Shaw J, Couper J, Kissane D, Price MA, et al. Are psychological interventions effective on anxiety in cancer patients? A systematic review and meta-analyses. Psychooncology 2018 Jun 09. [doi: 10.1002/pon.4794] [Medline: 29885258]

54. Fuertes JN, Boylan LS, Fontanella JA. Behavioral indices in medical care outcome: the working alliance, adherence, and related factors. J Gen Intern Med 2009 Jan;24(1):80-85 [FREE Full text] [doi: 10.1007/s11606-008-0841-4] [Medline: 18972089]

55. Taaffe DR, Newton RU, Spry N, Joseph D, Chambers SK, Gardiner RA, et al. Effects of Different Exercise Modalities on Fatigue in Prostate Cancer Patients Undergoing Androgen Deprivation Therapy: A Year-long Randomised Controlled Trial. Eur Urol 2017 Dec;72(2):293-299 [FREE Full text] [doi: 10.1016/j.eururo.2017.02.019] [Medline: 28249801]

56. Watson EK, Rose PW, Neal RD, Hulbert-Williams N, Donnelly P, Hubbard G, et al. Personalised cancer follow-up: risk stratification, needs assessment or both? Br J Cancer 2012 Jan 03;106(1):1-5 [FREE Full text] [doi: 10.1038/bjc.2011.535] [Medline: 22215103]

\author{
Abbreviations \\ 2MWT: two minute walk test \\ 6MWT: six minute walk test \\ BMI: body mass index \\ DVD: digital video disk \\ HBA $_{1 c}$ : hemoglobin $A_{1 c}$ \\ HRQoL: health-related quality of life \\ MVPA: moderate to vigorous physical activity \\ PA: physical activity \\ RCT: randomized controlled trial \\ SMS: short message service
}


Edited by C Dias; submitted 20.09.18; peer-reviewed by JA Hughson, D Mayer; comments to author 31.10.18; revised version received 08.11.18; accepted 13.11.18; published 12.02.19

Please cite as:

Kiss N, Baguley BJ, Ball K, Daly RM, Fraser SF, Granger CL, Ugalde A

Technology-Supported Self-Guided Nutrition and Physical Activity Interventions for Adults With Cancer: Systematic Review JMIR Mhealth Uhealth 2019;7(2):e12281

URL: http://mhealth.jmir.org/2019/2/e12281/

doi: $10.2196 / 12281$

PMID: $\underline{30747720}$

CNicole Kiss, Brenton James Baguley, Kylie Ball, Robin M Daly, Steve F Fraser, Catherine L Granger, Anna Ugalde. Originally published in JMIR Mhealth and Uhealth (http://mhealth.jmir.org), 12.02.2019. This is an open-access article distributed under the terms of the Creative Commons Attribution License (https://creativecommons.org/licenses/by/4.0/), which permits unrestricted use, distribution, and reproduction in any medium, provided the original work, first published in JMIR mhealth and uhealth, is properly cited. The complete bibliographic information, a link to the original publication on http://mhealth.jmir.org/, as well as this copyright and license information must be included. 